\title{
Comparison of 12-lead and computer-analysed 3 orthogonal lead electrocardiogram in coronary artery disease
}

\author{
R. G. Murray, A. R. Lorimer, F. G. Dunn, P. W. Macfarlane, I. Hutton, and \\ T. D. V. Lawrie \\ From the Department of Medical Cardiology, Royal Infirmary, Glasgow
}

The computer-analysed 3 orthogonal lead system (‘3-lead ECG’) provides a rapid and consistent interpretation of the electrocardiogram. In 102 patients undergoing selective coronary arteriography, the ability of such a system to predict the presence or absence of coronary artery disease and the site of myocardial ischaemia was compared with that of the conventional scalar electrocardiogram interpreted by cardiologists ('12-lead ECG'). Each system predicted the site of myocardial ischaemia with equal accuracy. The 3-lead ECG was a more sensitive index (3-lead ECG sensitivity $=77 \% ; 12$-lead ECG sensitivity=70\%) but less specific (3-lead $E C G$ specificity $=74 \% ; 12$-lead $E C G$ specificity $=78 \%$ ). In coronary artery disease, the predictive 'index of merit' for the 3-lead ECG was 0.51, compared with 0.48 for the 12-lead ECG. These results provide further justification for the routine use of the 3 orthogonal lead electrocardiogram.

The conventional scalar electrocardiogram has for many years proved a useful investigation in the diagnosis of myocardial ischaemia. The limitations of electrocardiography in this field have been stressed (Wood et al., 1950; Doyle et al., 1957; Master and Rosenfeld, 1967; Friesinger and Smith, 1972); approximately 50 per cent of patients with documented coronary atherosclerosis have normal resting electrocardiograms. Despite this, the scalar electrocardiogram remains one of the principal screening procedures in patients presenting with chest pain.

The introduction of selective coronary arteriography has provided a means of establishing the presence or absence of coronary atherosclerosis in the living patient (Kemp et al., 1967; Sones, 1972). Computer-assisted interpretation of the 3 orthogonal lead electrocardiogram has been in operation for some time in this hospital (Macfarlane and Lawrie, 1974) and has removed observer bias and variation in the diagnosis of abnormalities of the electrocardiogram.

It was, therefore, decided to evaluate the usefulness of the computerized electrocardiographic reporting system in the diagnosis of coronary artery

Received 19 December 1975. disease in patients undergoing selective coronary arteriography.

\section{Patients and methods}

One hundred and two patients presenting with chest pain warranting selective coronary arteriography were studied. The group consisted of 91 men and 11 women with a mean age of 46.8 years (range 32 to 64 years). Patients with rheumatic heart disease or on digitalis therapy were not included in the study.

Selective coronary arteriography was performed by the technique of Sones or Judkins (Sones and Shirey, 1962; Judkins, 1967). Coronary artery disease was considered to be present when reduction in lumen was greater than $\mathbf{5 0}$ per cent in one or more of the three major vessels (right, left anterior descending, and left circumflex coronary arteries). The patients were classified as having a normal vasculature, single, double, or triple vessel disease.

Conventional scalar 12-lead electrocardiograms were recorded using either a Cambridge Transrite 4 or Siemens Cardiostat apparatus. The electrocardiograms thus obtained were reported on independently by two of the authors without knowledge 
of the result of the coronary arteriogram. Any discrepancies in reporting were settled in committee. The diagnostic criteria for myocardial infarction and myocardial ischaemia were those in common use (Macfarlane, 1970).

Three orthogonal lead electrocardiograms were recorded using the modified axial system (Macfarlane, 1969). Electrocardiograms were tape recorded, using a multichannel FM tape recorder as described previously (Macfarlane et al., 1972), and were replayed to a PDP8E computing system for analysis using the programme which has been reported in detail elsewhere (Macfarlane and Lawrie, 1974). Essentially 8 seconds of leads $\mathrm{X}, \mathrm{Y}$, and $\mathrm{Z}$ were replayed simultaneously for interpretation and a typical complex was chosen for analysis. Multiple measurements were made by the programme and the interpretation was made on the basis of a check of over 200 criteria. In a previous paper (Cawood et al., 1974) discussing the day-to-day changes in the 3 orthogonal lead electrocardiogram after myocardial infarction, the criteria for the diagnosis of this abnormality were presented. For the detection of ischaemic changes, multiple measurements of the ST-T segment were made. Full details of the criteria used will be published elsewhere (Macfarlane and Lawrie, 1977). In summary the ST-T segment was divided into eight equal time intervals and the amplitude at the end of each was measured. This allowed the detection of ST abnormalities in the early part of the ST-T segment and of terminal $T$ wave abnormalities in the late ST-T segment. In addition, the total negative area of the ST-T segment was measured and compared with normal. The other criterion used for the diagnosis of myocardial ischaemia was an abnormal $T$ vector orientation in either the frontal or transverse plane denoted $T_{F}$ and $T_{T}$, respectively. The more important criteria for ischaemic changes can be summarized as follows.

(a) $\mathrm{T}_{\mathrm{F}}<10^{\circ}$ or $\mathrm{T}_{\mathrm{T}}>70^{\circ}$.

(b) $\mathrm{T}_{\mathrm{X}}<0.05 \mathrm{mV}$ or $\mathrm{T}_{\mathrm{Y}}<0.05 \mathrm{mV}$ or $\mathrm{T}_{\mathrm{z}}<-0.05$ $\mathrm{mV}$.

(c) Depression of the ST onset by $0.02 \mathrm{mV}$ or more, together with a flat or downward sloping ST segment in lead $\mathrm{X}, \mathrm{Y}$, or $\mathrm{Z}$.

(d) Inversion of the terminal portion of the $T$ wave in lead $\mathrm{X}, \mathrm{Y}$, or $\mathrm{Z}$.

The computer reports thus obtained were reviewed without knowledge of the result of the coronary arteriogram or of the 12-lead electrocardiogram report. Coronary arteriographic assessment of the presence or absence of coronary artery disease was accepted as correct and the sensitivity and specificity (Table 1) of the 3-lead and 12-lead systems were calculated. The 'index of merit' of
Hanssen and Kuipers (1965) was adapted to assess the value of each system in predicting the presence or absence of coronary artery disease (Table 2). The site of myocardial ischaemia predicted from the

\section{TABLE 1 Formulae for sensitivity and specificity}

$$
\begin{aligned}
& \text { Sensitivity }=\frac{a_{1}}{a_{2}} \times 100 \% \\
& \text { Specificity }=\frac{a_{3}}{a_{4}} \times 100 \%
\end{aligned}
$$

The coronary arteriographic diagnosis is regarded as correct. $a_{1}$, number with correct ischaemic electrocardiograms; $a_{2}$, number with coronary artery disease; $a_{3}$, number with correct normal electrocardiograms; $a_{4}$, number with normal vessels.

TABLE 2 Calculation of index of merit (Hanssen and Kuipers, 1965)

\begin{tabular}{lll}
\hline Truth & \multicolumn{2}{l}{ Prediction } \\
\hline & Yes & No \\
\cline { 2 - 3 } Yes & $\mathrm{n}_{1}$ & $\mathrm{n}_{2}$ \\
No & $\mathrm{n}_{3}$ & $\mathrm{n}_{4}$ \\
\hline
\end{tabular}

$$
\begin{aligned}
\text { Index of merit } & =\frac{n_{1}}{n_{1}+n_{2}}+\frac{n_{4}}{n_{3}+n_{4}}-1 \\
& =\frac{a_{1}}{a_{2}}+\frac{a_{3}}{a_{4}}-1 \quad \text { (cf Table 1) } \\
& =\frac{1}{100} \text { (sensitivity+ specificity) }-1
\end{aligned}
$$

YES and NO refer to presence or absence of coronary artery disease. The coronary arteriogram result is regarded as 'TRUTH'. The number of cases in each category is given by $n_{1} \ldots n_{4}$. The fraction of correct positives

is $\frac{n_{1}}{n_{1}+n_{2}}$, that of correct negatives is $\frac{n_{4}}{n_{3}+n_{4}}$.

TABLE 3 Expected location of arteriographic occlusion associated with myocardial infarction (Fames, 1968)

\begin{tabular}{ll}
\hline Site of infarct & Associated arterial disease \\
\hline Anteroseptal & LAD \\
Anterior & LAD \\
Anterolateral & LAD $\mathbf{L C}_{\mathbf{x}}$ \\
High lateral & LC \\
Inferior & RCA (if right coronary dominant) \\
& LC (if left coronary dominant) \\
True posterior & RCA (if right coronary dominant) \\
& LC \\
&
\end{tabular}

Abbreviations: $\mathrm{LAD}=$ left anterior descending coronary artery. $\mathrm{LC}_{\mathrm{x}}=$ left circumflex coronary artery. $\mathrm{RCA}=$ right coronary artery. 
electrocardiogram using each lead system was compared with that predicted from the coronary arteriogram. The expected arterial supply to the various areas of the left ventricular myocardium is summarized in Table 3 (James, 1968).

\section{Results}

Twenty-five patients had a normal coronary vasculature on selective coronary arteriography, while 77 patients $(75 \%)$ were shown to have significant lesions affecting one or more vessels.

TABLE 4 Distribution of coronary artery disease in 77 patients

\begin{tabular}{llc}
\hline Coronary arteriogram & Vessel affected & $\begin{array}{l}\text { No of } \\
\text { patients }\end{array}$ \\
\hline Single vessel disease (13) & RCA & 4 \\
& LAD & 9 \\
& LC $_{x}$ & - \\
Double vessel disease (29) & RCA +LAD & 20 \\
& RCA+LC & 4 \\
& LAD +LC & 5 \\
Triple vessel disease (35) & RCA +LAD+LC & 35
\end{tabular}

Abbreviations as for Table 3 .

Number in brackets equals total number of patients in each group.

TABLE 5 12-lead electrocardiogram report related to the coronary arteriogram in 92 patients $\star$

\begin{tabular}{lcc}
\hline Coronary arteriogram & $\begin{array}{l}\text { Normal } \\
\text { electrocardiogram }\end{array}$ & $\begin{array}{l}\text { Ischaemic } \\
\text { electrocardiogram }\end{array}$ \\
\hline Normal (23) & $18(78 \%)$ & 5 \\
Single vessel disease (11) & 5 & $6(54 \%)$ \\
$\begin{array}{l}\text { Double vessel disease (27) } \\
\text { Triple vessel disease (31) }\end{array}$ & 6 & $17(63 \%)$ \\
$\begin{array}{l}\text { Coronary artery disease } \\
\text { Total (69) }\end{array}$ & 21 & $25(81 \%)$ \\
\end{tabular}

*Excluding those with left ventricular hypertrophy or left bundle-branch block on 12-lead electrocardiogram.

TABLE 6 'Ischaemic' electrocardiogram (12-lead system) related to the coronary arteriogram $\star$

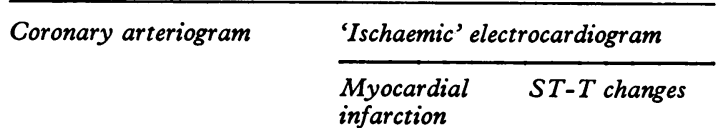

\begin{tabular}{lrr}
\hline Single vessel disease & 3 & 3 \\
Double vessel disease & 11 & 6 \\
Triple vessel disease & 13 & 12
\end{tabular}

^Excluding those with left ventricular hypertrophy or left bundle-branch block on 12-lead electrocardiogram.
Of those with coronary artery disease, 13 patients had single vessel disease, 29 double vessel disease, and 35 triple vessel disease. The distribution of affected vessels is shown in Table 4.

\section{2-lead electrocardiogram}

Four electrocardiographic categories were encountered in this study: (i) normal tracing, (ii) 'myocardial ischaemia', either with evidence of a transmural infarct, or with ischaemic repolarization abnormalities, (iii) left ventricular hypertrophy (LVH), and (iv) left bundle-branch block (LBBB). The latter two diagnoses (LVH and LBBB) were present in 8 and 2 patients, respectively. Of those with $\mathrm{LVH}, 2$ patients were hypertensive (BP > $140 / 90 \mathrm{mmHg}(18 \cdot 6 / 12.0 \mathrm{kPa})$ ); the remainder were normotensive at the time of study. Excluding these two categories, the 12-lead electrocardiogram was normal in 18 out of 23 patients with normal vessels (Table 5). Five patients with normal vessels had 'ischaemic' electrocardiograms, the changes being restricted to repolarization abnormalities (specificity $=78 \%$ ).

The resting 12-lead electrocardiogram was ischaemic in 48 out of 69 patients with coronary artery disease (sensitivity $=70 \%$ ). The electrocardiographic criteria for myocardial ischaemia were satisfied more frequently as the extent of coronary artery disease increased (Table 5). The criteria for myocardial infarction were fulfilled in 27 of the 48 'ischaemic' electrocardiograms $(56 \%)$. The frequency with which electrocardiographic evidence of transmural infarction occurred did not correlate with the extent of disease (Table 6). In all instances of myocardial infarction, the site of ischaemia predicted from the 12-lead electrocardiogram agreed with that predicted from the coronary arteriogram.

The 'index of merit' of the 12-lead system in predicting the presence or absence of coronary artery disease was 0.47 .

TABLE 7 3-lead electrocardiogram report related to the coronary arteriogram in 89 patients*

\begin{tabular}{lcc}
\hline Coronary arteriogram & $\begin{array}{l}\text { Normal } \\
\text { electrocardiogram }\end{array}$ & $\begin{array}{c}\text { 'Ischaemic' } \\
\text { electrocardiogram }\end{array}$ \\
\hline Normal (23) & $17(74 \%)$ & 6 \\
Single vessel disease (11) & 4 & $7(64 \%)$ \\
Double vessel disease (25) & 6 & $19(76 \%)$ \\
Triple vessel disease (30) & 5 & $25(83 \%)$ \\
\hline Coronary artery disease & & \\
Total (66) & 15 & $51(77 \%)$ \\
\hline
\end{tabular}

$\star$ Excluding those with left ventricular hypertrophy or left bundle-branch block on 3-lead electrocardiogram. 


\section{3-lead electrocardiogram}

Computer-assisted orthogonal 3-lead electrocardiogram reports also fell into the same four categories (normal, 'myocardial ischaemia', left ventricular hypertrophy, and left bundle-branch block). The latter two diagnoses were made in 11 and 2 patients, respectively. Of those with left ventricular hypertrophy, 2 patients were hypertensive (BP $>$ $140 / 90 \mathrm{mmHg}(18 \cdot 6 / 12.0 \mathrm{kPa}))$; the other 9 were normotensive at the time of study. Excluding these two diagnoses, the resting 3-lead electrocardiogram was normal in 17 out of 23 patients with normal vessels (specificity $=74 \%$ ). In 5 patients repolarization abnormalities were reported and in one patient an inferior myocardial infarction was diagnosed.

The 3-lead electrocardiogram diagnosed 'myocardial ischaemia' in 51 of 66 patients with coronary artery disease (sensitivity $=77 \%$ ) (Table 7 ). The diagnosis was made with increasing frequency with increasing extent of coronary artery disease. Transmural myocardial infarction was reported in $25(49 \%)$ of the patients with 'ischaemic' electrocardiograms (Table 8). Again, no correlation was apparent between the frequency with which myocardial infarction was diagnosed and the extent of disease. As with the 12-lead system, the predicted site of ischaemia agreed with that predicted from the coronary arteriogram in all cases of myocardial infarction.

The 'index of merit' for the 3-lead system in predicting the presence or absence of coronary artery disease was 0.51 .

\section{Comparison of reports}

In 88 patients $(86 \%)$, the 12-lead and 3-lead electrocardiogram reports were identical. The discordant reports are listed in Table 9. In 6 patients
TABLE 8 'Ischaemic' electrocardiogram (3-lead system) related to the coronary arteriogram ${ }^{\star}$

\begin{tabular}{lll}
\hline Coronary arteriogram & \multicolumn{2}{c}{ 'Ischaemic' electrocardiogram } \\
\cline { 2 - 3 } & $\begin{array}{ll}\text { Myocardial } \\
\text { Infarction }\end{array}$ & $S T$-T changes \\
& 3 & 4 \\
Single vessel disease & 9 & 10 \\
Double vessel disease & 9 & 12 \\
Triple vessel disease & 13 &
\end{tabular}

«Excluding those with left ventricular hypertrophy or left bundle-branch block on 3-lead electrocardiogram.

with proven coronary artery disease $(8 \%)$ the 3-lead electrocardiogram diagnosed 'myocardial ischaemia' not reported by the 12-lead system. However, in 4 patients with proven coronary artery disease and 'ischaemic' 12-lead electrocardiograms, the 3-lead system reported left ventricular hypertrophy with accompanying $S T$ and $T$ wave abnormalities. The reverse was reported in one patient. In all, left ventricular hypertrophy was diagnosed in 12 patients, 11 by the 3-lead and 8 by the 12-lead system. One patient had normal vessels, but the remainder had coronary artery disease. Left ventricular hypertrophy was reported, therefore, by the 3-lead system in 13 per cent of patients with coronary artery disease and by the 12-lead system in 9 per cent. Two of these patients were hypertensive $(\mathrm{BP}>140 / 90 \mathrm{mmHg}(18.6 / 12.0 \mathrm{kPa}))$; the remainder were normotensive (mean BP 131/76 $\mathrm{mmHg}(17 \cdot 4 / 10 \cdot 1 \mathrm{kPa}))$.

\section{Discussion}

The number of 'ischaemic' electrocardiograms in both systems is higher than reported by certain

TABLE 9 Discordant 3-lead and 12-lead electrocardiogram reports in 14 patients

\begin{tabular}{lll}
\hline Coronary arteriogram & 12-lead report & 3-lead report \\
\hline Normal & $\begin{array}{l}\text { Normal } \\
\text { Inferolateral ischaemia }\end{array}$ & $\begin{array}{l}\text { Inferior ischaemia } \\
\text { Inferior infarction }\end{array}$ \\
$\begin{array}{l}\text { Single vessel disease } \\
\text { LAD }\end{array}$ & Normal & Anterolateral ischaemia \\
$\begin{array}{l}\text { Double vessel disease } \\
\text { RCA+LAD }\end{array}$ & Normal & \\
RCA+LAD & Normal & Inferior ischaemia \\
RCA+LAD & Anteroseptal infarction & Anterolateral ischaemia \\
RCA+LAD & Normal & Left ventricular hypertrophy \\
RCA+LAD & Inferior ischaemia & Inferolateral ischaemia \\
RCA+LC & Normal & Left ventricular hypertrophy \\
Triple vessel disease & True posterior infarction \\
(RCA+LAD+LC & Lateral ischaemia & Left ventricular hypertrophy \\
& Anterolateral infarction & Anterolateral ischaemia \\
& Normal & Subepicardial ischaemia \\
& Left ventricular hypertrophy & Anterolateral ischaemia \\
& Anterolateral ischaemia & Left ventricular hypertrophy \\
\hline
\end{tabular}


authors (Wood et al., 1950; Doyle et al., 1957; Master and Rosenfeld, 1967; Hultgren et al., 1967; Friesinger and Smith, 1972) in patients suspected of having coronary atherosclerosis. Others have reported a similar proportion of abnormal electrocardiograms in patients with clinical ischaemic heart disease and unequivocal coronary artery disease (Elliott and Gorlin, 1966). This discrepancy may be explained by patient selection since, in this study, the majority of patients were drawn from a second referral clinic, often presenting with typical cardiac ischaemic pain. Such a group does not, therefore, represent a true cross-section of the coronary atherosclerosis population.

The 3 orthogonal lead electrocardiogram reporting system described has been shown to predict more accurately the presence or absence of coronary artery disease subsequently proven by selective coronary arteriography (index of merit for 3-lead system $=0.51$, and for 12-lead system $=0.48$ ). It is not feasible to test for a statistically significant difference between these two indices. It is possible to show that there is no statistically significant difference between corresponding components of the index of merit, viz. the fractions of correct positives and correct negatives (Table 2), obtained from 3-lead and 12-lead electrocardiograms. It should be noted, however, that this index is designed to show up differences between diagnostic methods on a scale of 0 to 1 . If the sensitivity is 100 per cent and specificity is 0 per cent, then the index of merit is 0 ; likewise if both sensitivity and specificity are 50 per cent then the index of merit is also 0 . If both sensitivity and specificity are ideal at 100 per cent then the index of merit has the optimal value of 1 . Thus, the higher the index of merit, the better the technique.

The 3-lead electrocardiogram was a more sensitive index of the presence of coronary artery disease but slightly less specific compared with the 12-lead electrocardiogram. With both systems, the predicted site of myocardial infarction correlated closely with the area of ischaemia predicted from the coronary arteriogram. False positive reports (i.e. 'ischaemic' electrocardiograms in patients with normal coronary vessels) were common with both 3-lead and 12-lead systems. The ischaemic abnormalities encountered were restricted in all but one patient to repolarization changes. The high frequency of 'ischaemic' electrocardiograms in the normal vessel group is not really surprising. The population studied, as discussed above, could scarcely be considered normal since none was asymptomatic. In addition, the paradox of angina pectoris in the presence of normal coronary vessels is well established (Kemp et al., 1973; James, 1970; Waxler, Kimbris, and
Dreifus, 1971; Eliot and Bratt, 1969; Likoff, Segal, and Kasparian, 1967). Many of these patients have objective evidence of myocardial ischaemia, either on the electrocardiogram or on exercise testing or atrial pacing with coronary sinus lactate sampling (Dwyer, Wiener, and Cox, 1969; Bemiller, Pepine, and Rogers, 1973; Arbogast and Bourassa, 1973; Helfant et al., 1970; Boudoulas et al., 1974).

Left ventricular hypertrophy was a fairly common electrocardiographic diagnosis in the patients with coronary artery disease (3-lead system $13 \%$; 12-lead system $9 \%$ ). Left ventricular hypertrophy in coronary artery disease (in the absence of hypertension) has been reported in necropsy studies (Ellis et al., 1962; McCain, Klein, and Gilson, 1950; Murata et al., 1972) while haemodynamic and angiographic studies in vivo have shown increased left ventricular mass in patients with coronary artery disease compared with those with normal coronary arteriograms (Pech et al., 1974). Hence, in the absence of a recognized predisposing factor to left ventricular hypertrophy, such an abnormality may well be a further index of myocardial ischaemia. If this were accepted, the sensitivity of the 3-lead electrocardiogram in diagnosing coronary artery disease would rise to 80 per cent and of the 12-lead to 72 per cent, altering the specificity to 71 per cent for the 3-lead and 75 per cent for the 12-lead electrocardiogram.

In a recent paper, Talbot et al. (1973) argued that the 3-lead and 12-lead systems of recording were complementary and that all 15 leads were 'essential' for computer-assisted electrocardiographic interpretation. Our own opinion is that the diagnostic gain in adopting such an approach is negligible when adequate criteria for the 3-lead electrocardiogram are chosen. Furthermore, the increase in computer time to undertake adequate wave recognition procedures on 15 leads so prolongs the analysis that it could become uneconomic. In this particular study, 86 per cent of patients had identical reports. The use of 12 conventional leads as well as the 3 orthogonal leads would have led to $4(4 \%)$ additional reports of myocardial ischaemia or infarction. In each case, however, ST-T abnormalities were already detected by the computer-analysed electrocardiogram but placed in the diagnostic category of left ventricular hypertrophy. Conversely the use of 3 orthogonal leads in addition to the 12 conventional leads would have led to a further 5 $(5 \%)$ reports of myocardial ischaemia or infarction in patients with single, double, or triple vessel disease who had normal 12-lead electrocardiograms.

In summary, the 3-lead electrocardiogram has been shown to have an enhanced 'index of merit' 
for the prediction of the presence or absence of coronary artery disease and has an equal ability to indicate the site of myocardial ischaemia compared with the 12-lead electrocardiogram. The technique is more sensitive than the 12-lead electrocardiogram but at the expense of slight lessening of specificity. This favourable performance provides further justification for the routine use of 3 orthogonal lead electrocardiography.

\section{References}

Arbogast, R., and Bourassa, M. G. (1973). Myocardial function during atrial pacing in patients with angina pectoris and normal coronary arteriograms. American Fournal of Cardiology, 32, 257.

Bemiller, C. R., Pepine, C. J., and Rogers, A. K. (1973). Long-term observations in patients with angina and normal coronary arteriograms. Circulation, 7, 36.

Boudoulas, H., Cobb, T. C., Leighton, R. F., and Wilt, S. M. (1974). Myocardial lactate production in patients with angina-like chest pain and angiographically normal coronary arteries and left ventricle. American fournal of Cardiology, 34, 501.

Cawood, H. T., Hillis, S., Macfarlane, P. W., and Lawrie, T. D. V. (1974). Day to day variation in 3 orthogonal lead electrocardiogram parameters after acute myocardial infarction. British Heart Fournal, 36, 1231.

Doyle, J. T., Heslin, A. S., Hilleboe, H. F., Formel, P. F., and Korms, R. F. (1957). A prospective study of degenerative cardiovascular disease in Albany: report of three years experience-1. Ischaemic heart disease. American Fournal of Public Health, 47, Suppl. April, 25.

Dwyer, E. M., Wiener, L., and Cox, J. W. (1969). Angina pectoris in patients with normal and abnormal coronary arteriograms. American fournal of Cardiology, 23, 639.

Eliot, R. S., and Bratt, G. (1969). The paradox of myocardial ischemia and necrosis in young women with normal coronary arteriograms. American fournal of Cardiology, 23, 633.

Elliott, W. C., and Gorlin, R. (1966). The coronary circulation, myocardial ischemia and angina pectoris (11). Modern Concepts of Cardiovascular Disease, 35, 117.

Ellis, L. B., Allison, R. B., Rodriguez, F. L., and Robbins, S. L. (1962). Relation of the degree of coronary-artery disease and of myocardial infarctions to cardiac hypertrophy and chronic congestive heart failure. New England Fournal of Medicine, 266, 525.

Friesinger, G. C., and Smith, R. F. (1972). Correlation of electrocardiographic studies and arteriographic findings with angina pectoris. Circulation, 46, 1173.

Hanssen, A. W., and Kuipers, W. J. A. (1965). On the relationship between the frequency of rain and various meteorological parameters (with reference to the problem of objective forecasting). Kaninklijk Nederlands Meteorologisch Instituut. Mededelingen en Verhandelingen, No. 81.

Helfant, R. H., Forrester, J. S., Hampton, J. R., Haft, J. I., Kemp, H. G., and Gorlin, R. (1970). Coronary heart disease. Differential hemodynamic, metabolic and electrocardiographic effects in subjects with and without angina pectoris during atrial pacing. Circulation, 42, 601.

Hultgren, H., Calciano, A., Platt, F., and Abrams, H. (1967). A clinical evaluation of coronary arteriography. American Fournal of Medicine, 42, 228.
James, T. N. (1968). The coronary circulation and conducting system in acute myocardial infarction. Progress in Cardiovascular Diseases, 10, 410.

James, T. N. (1970). Angina without coronary disease (sic). Circulation, 42, 189.

Judkins, M. P. (1967). Selective coronary arteriography. Radiology, 89, 815.

Kemp, H. G., Evans, H., Elliott, W. C., and Gorlin, R. (1967). Diagnostic accuracy of selective coronary cinearteriography. Circulation, 36, 526.

Kemp, H. G., Vokonas, P. S., Cohn, P. F., and Gorlin, R. (1973). The anginal syndrome associated with normal coronary arteriograms. American fournal of Medicine, 54, 735.

Likoff, W., Segal, B. L., and Kasparian, H. (1967). Paradox of normal selective coronary arteriograms in patients considered to have unmistakable coronary heart disease. New England fournal of Medicine, 276, 1063.

McCain, F. H., Kline, E. M., and Gilson, J. S. (1950). A clinical study of 281 autopsy reports on patients with myocardial infarction. American Heart fournal, 39, 263.

Macfarlane, P. W. (1969). A modified axial lead system for orthogonal lead electrocardiography. Cardiovascular Research, 3, 510.

Macfarlane, P. W. (1970). Computer studies in electrocardiography. Ph.D.Thesis, University of Glasgow.

Macfarlane, P. W., Cawood, H., Taylor, T. P., and Lawrie, T. D. V. (1972). Routine automated electrocardiogram interpretation. Bio-Medical Engineering, 7, 176.

Macfarlane, P. W., and Lawrie, T. D. V. (1974). An Introduction to Automated Electrocardiogram Interpretation. Butterworths, London.

Macfarlane, P. W., and Lawrie, T. D. V. (1977). Introductory 3 Lead ECG Interpretation. Butterworths, London. In the press.

Master, A. M., and Rosenfeld, I. (1967). Exercise electrocardiography as an estimation of cardiac function. Diseases of the Chest, 51, 347.

Murata, K., Terasawa, F., Kuramochi, M., Ikeda, M., and Seki, M. (1972). The relation of blood pressure and degree of coronary atherosclerosis to myocardial lesions and cardiac hypertrophy. Fapanese Heart fournal, 13, 34 .

Pech, H. J., Witte, J., Romaniuk, R., Parsi, R. A., and Porstmann, W. (1974). Left ventricular mass in coronary artery disease without hypertension. British Heart fournal, 36, 362.

Sones, F. M., Jr. (1972). Indications and value of coronary arteriography. Circulation, 46, 1155.

Sones, F. M., Jr., and Shirey, E. K. (1962). Cine coronary arteriography. Modern Concepts of Cardiovascular Disease, 31, 735.

Talbot, S., Dreifus, L. S., Watanabe, Y., Reich, M., Chiang, R., and Morris, K. (1973). Diagnostic accuracy of a 15lead hybrid computer-aided electrocardiographic system. European fournal of Cardiology, 1, 29.

Waxler, E. B., Kimbiris, D., and Dreifus, L. S. (1971). The fate of women with normal coronary arteriograms and chest pain resembling angina pectoris. American fournal of Cardiology, 28, 25.

Wood, P., McGregor, M., Magidson, O., and Whittaker, W. (1950). The effort test in angina pectoris. British Heart fournal, 12, 363.

Requests for reprints to Dr. A. R. Lorimer, Department of Medical Cardiology, Royal Infirmary, Glasgow G4 OSF. 